\title{
Exemplary Educators Who Embrace a Teaching Philosophy Guided by a Pedagogy of Kindness
}

\author{
Elizabeth Gorny-Wegrzyn*, Beth Perry \\ Athabasca University, Canada \\ Email: egornywegrzyn@athabascau.ca
}

\begin{abstract}
The purpose of this literature review was to explore scholarly and grey literature on teaching approaches to pedagogy in higher education, with a focus on the pedagogy of kindness. For the analysis, we reviewed six research reports from peer-reviewed journals on the pedagogy of kindness, three books written by acclaimed theorists on critical pedagogy and the pedagogy of hope, and seven articles from grey literature. The questions addressed were, what does the literature reveal are the effects of a pedagogy of kindness on the learning environment, and what are the outcomes for learners when educators embrace this teaching philosophy? Does the employ of kindness in teaching influence learners' attitudes about issues surrounding social justice? Further, are there links between being an exemplary educator, teaching success, and the enactment of a pedagogy of kindness? In this paper, we examine emerging themes related to how this teaching philosophy impacts learners and the learning environment and the connection between a pedagogy of kindness and traits of exemplary educators. Finally, these themes guided a discussion on the implications for practice. In sum, the literature revealed that a teaching model based on a pedagogy of kindness enhances the performance of outstanding educators and increases their success in teaching. Moreover, this philosophy positively influences students, their learning environments, their educational achievements, and heightens their social consciousness.
\end{abstract}

Keywords: pedagogy of kindness, higher education, teaching excellence, exemplary teachers, critical pedagogy.

"You can teach a student a lesson for a day; but if you can teach him to learn by creating curiosity, he will continue the learning process as long as he lives." Clay P. Bedford

(Edberg, 2020)

\section{Introduction}

Teaching excellence in higher education is a complicated concept that involves many nuances and characteristics that have been widely debated by academics and researchers (Serbati et al., 2020). Some questions considered by these scholars are, what constitutes excellence in teaching, what are the responsibilities of educators, and what teaching philosophies do exemplary teachers embrace? Other educational issues deliberated throughout history include the purpose of education, the rights of learners, and the focus of syllabi based on social and political conditions of the time (Serbati et al., 2020; Siegel, 2010). From ancient times to the present, there subsists a social structure in our higher education academies that is sometimes oppressive, paternalistic, and domineering (Breuing, 2011). This hierarchal construct, which gives teachers power and authority but students none, can be repressive and denies students an active voice in their learning (Breuing, 2011; Giroux, 1997; Thomas, 2019; Weiler, 2001). At the same time, oppressive authority does not allow for a free exchange of ideas and discourse on social injustices, and therefore it inhibits social awareness (concerning equality in race, gender, age, class, and culture) (Breuing, 2011; Giroux, 1997).

Theorists of pedagogy study teaching philosophies that can help eliminate the inequity of this power imbalance and allow students to become partners in the teaching and learning process. Pedagogical models like critical pedagogy (Breuing, 2011; Giroux, 1997; Weiler, 2001), the pedagogy of hope (hooks, 2003), and the pedagogy of kindness (Clegg \& Rowland, 2010; Groves et al., 2015; Hativa et al., 2001; Khan \& Armstrong, 2019; Loreman, 2011; Magnet et al., 2014; Serbati et al., 2020; Thomas, 2019) can 
empower learners, allow them to think independently, and engage them more fully thereby improving their academic achievements and increasing their social awareness. Outstanding educators use these teaching philosophies to inspire learners to be more successful academically, and teachers who embrace these philosophies also become more successful educators (Denial, 2019; Henard \& Roseveare, 2012; Khan \& Armstrong, 2019; Loreman, 2011; Serbati et al., 2020). As well, exemplary teachers who have an elevated level of identification with students (i.e., a better understanding of their diversity in terms of ability, culture, religion, and language) encourage discussion on social justice and can facilitate changes in attitudes on social inequities (Giroux, 1997; Loreman, 2011).

The purpose of this literature review was to explore peer-reviewed and grey literature on teaching approaches to pedagogy in higher education, with a focus on the pedagogy of kindness. In this paper, we address the questions, what does the literature reveal are the effects of a pedagogy of kindness on the learning environment, and what are the outcomes for learners when educators adopt this teaching philosophy? Does the use of kindness as a teaching strategy influence learners' attitudes about issues surrounding social justice? Further, are there links between being an exemplary educator, teaching success, and the enactment of a pedagogy of kindness?

\section{Literature Search Strategy}

The search engines, Bielefeld Academic Search Engine (BASE), Connecting Repositories (CORE), and Google Scholar, were accessed through the Athabasca University library and used to locate articles pertaining to this literature review. Google was also used to find additional grey literature. The keyword terms, pedagogy of kindness, higher education, teaching excellence, teaching strategies, and exemplary teachers were applied to the search resulting in 132 articles of potential interest. Subsequently, articles not written in English, and those that did not mention higher education pedagogy in their abstracts, were eliminated. Thirty papers remained for further consideration.

The remaining 30 articles were read and assessed for potential relevance to the purpose of this paper. Inclusion criteria included articles written in English; published between 2000 and 2020; focused on higher education; and those that were research studies, government publications, documents from educational institutions, or reviews and expert opinion pieces on teaching strategies that use kindness, caring, and empathy as a foundation to pedagogy. Excluded were articles that did not meet the stated inclusion criteria.

\subsection{Evaluation of Quality of the Literature}

The critical appraisal skills program (CASP) was used to assess research articles that met the inclusion criteria (CASP, 2018). CASP is a tool used to ascertain if a research study has validity, and if the study produced results that can be helpful to other groups and communities (CASP, 2018). CASP is comprised of ten questions that help someone reading a research article appraise evidence and determine the value of the paper (CASP, 2018). High quality studies include factors such as a clearly defined purpose of the research, study methodology and study design appropriate to the study aim, evidence of rigour and lack of bias in the research, and reliability and generalizability of the study results (CASP, 2018). CASP does not score the article directly but assists the reader in assessing the strength of the evidence presented (CASP, 2018). Six research studies from peer-reviewed journals met all inclusion criteria and were considered of good or high quality based on a CASP assessment.

The ACCODS (authority, accuracy, coverage, objectivity, date, significance) checklist was used to appraise the quality of grey literature (Tyndall, 2010). ACCODS is a tool that can help evaluate grey literature, such as government and organizational documents, reports and conference papers, and unpublished papers and studies (Tyndall, 2010). ACCODS supplies six standards with prompts for appraising the quality of grey information. These standards consist of: the authority (reputation) of the author or organization; the accuracy (clearly stated aim) of the paper; the coverage (clearly stated parameters or limits); objectivity (clearly stated position); the date of the article (to confirm consequence), and the significance of the paper to the review (to add meaning and value) (Tyndall, 2010). Seven papers from grey literature, and three books on pedagogy met all inclusion criteria and were considered of good or high quality based on an ACCORDS assessment. 
In total, 13 articles and three books were included in this analysis. These papers consisted of four peer-reviewed studies that used qualitative and quantitative methods, one case study of two cohorts of university students that used mixed methods, and one literature review. The three books were authored by renowned theorists on pedagogical philosophies. The remaining seven articles from grey literature included valuable documents, summaries, and information from government and higher education institution databases, as well as expert opinion pieces on teaching strategies. All the literature reviewed was relevant to the overarching purpose of this appraisal, exploring the impact of using kindness as an approach to pedagogy in higher education.

\section{Analysis of Data}

\subsection{Pedagogical Models and Teaching Excellence}

This literature review deliberated three philosophical pedagogies: critical pedagogy, the pedagogy of hope, and the pedagogy of kindness. Each philosophy promotes the use of effective teaching strategies that engage students and allows them to broaden their academic minds and their social awareness. Each pedagogical model also carries responsibilities for the educator as a facilitator in expanding learners' minds and encouraging them to think independently. This review focused on the pedagogy of kindness, though other teaching philosophies mentioned earlier are just as valid and can help sustain teaching excellence and success in teaching.

To ensure that quality in teaching and learning is maintained, theorists discuss different models of higher education pedagogy. Critical pedagogy endorses practical experiences in conjunction with theory (both in the classroom and outside in the real world), is student-centered, and is emancipatory for learners of diverse backgrounds and life experiences (Breuing, 2011; Giroux, 1997). Critical pedagogy is also politically oriented and encourages open discussion of social injustices to enhance learner social awareness (Breuing, 2011; Giroux, 1997). As well, the pedagogy of hope, described by hooks (2003) in her book, Teaching Community: A Pedagogy of Hope, is a teaching philosophy that advocates for equal partnership between educators and learners. Hooks' teaching model supports the idea of community, both in the academy and in the world at large (2003). A pedagogy of hope promotes learning environments that encourage the exchange of ideas and thoughts among students and thus can expand minds and enhance social consciousness (hooks, 2003).

\subsection{Pedagogy of Kindness}

At present, there continues to be social injustice in the world concerning inequality and inequity, especially in matters of race, gender, culture, age, and religion. It is in part the responsibility of educators to expand learners' minds and social awareness through academic strategies that engage them in group discussions so that they can actively voice their opinions and become aware of different life experiences and thoughts of others. Giroux (1997) writes that emancipatory authority allows students to bring their unique life histories to a class where, through discussion, these experiences are shared and become critical knowledge for all. Such strategies, as used in the pedagogy of kindness, can encourage community collaboration and help eliminate hierarchal power structures in academia (Magnet et al., 2014).

The literature reveals that kindness can be used as an enriching strategy in higher education pedagogy. Cambridge University Press (n.d.) defines kindness as "the quality of being generous, helpful, and caring about other people, or an act showing this quality." Magnet et al. (2014) argue that historically the concept of kindness has been feminized and devalued and that higher education institutions exploit it to preserve hierarchies and power structures. The authors state that kindness is "a project inflected by assumptions around gender, race, class, and ability, as is the history of emotions themselves" (Magnet et al., 2014, p.4). Yet despite the corrupt use of kindness identified by Magnet et al. (2014), they also assert that being kind, as a pedagogical strategy, can eliminate dominance, oppression, and competition in the academy. The pedagogy of kindness allows students from diverse cultures and backgrounds to become empowered, have an active voice in their learning experiences, become more engaged with academic and social activities, feel more worthy as students and as human 
beings, and see the worth of others (Clegg \& Rowland, 2010; Groves et al., 2015; Hativa et al., 2001; Khan \& Armstrong, 2019; Loreman, 2011; Magnet et al., 2014; Serbati et al., 2020; Thomas, 2019). This teaching philosophy positively influences learning environments, improves learner outcomes, enhances student social awareness, and increases teaching success (Clegg \& Rowland, 2010; Magnet et al., 2014).

Magnet et al. (2014) write that kindness is "a tactic of intellectual community building" (p.10). Compassion and understanding allow the building of strong and unified student-teacher relationships while acknowledging the differences in the privilege of their positions and thereby promoting selfreflection and accountability (Magnet et al., 2014). The authors reject a pedagogical model that shames or humiliates students. Instead, Magnet et al. (2014) suggest that kindness can help engage students and inspire them to be responsible in an academic setting. Thoughtfulness and care promote an educatorstudent connection that encourages the abilities of learners and is attentive to their interests while also stimulating consideration for the needs and interests of others (Magnet et al., 2014).

In the same sense, Clegg and Rowland (2010) explored kindness in higher education pedagogy through their qualitative study of students' reflections on their relationships with instructors. This study found that though students appreciated kindness from educators and readily recognized it as an attribute of good teachers, institutional administrators did not adequately value its importance in pedagogical practice. Clegg and Rowland (2010) note that addressing kindness in higher education pedagogy unsettles the established systems of the institution, those of "neo-liberal assumptions that place value on utility and cost above other human values" (p. 720). Therefore, many criticize kindness as a quality in educators as being inappropriate, emotional, and lacking rigour in an academic setting (Clegg \& Rowland, 2010). The authors argue that kindness can be both beneficial and rigorous, entailing focus on the interests of others who may have different values and needs from our own (Clegg \& Rowland, 2010). One quality of a good educator (and of a human being that values others) is the ability to identify with someone and the capacity to see things from their viewpoint. This quality can benefit student outcomes in that students become more engaged, try harder, and get better grades in classes where educators encourage learners to voice their opinions and to value the thoughts of classmates (Clegg \& Rowland, 2010).

Increasingly educators realize the benefits of adopting a teaching philosophy guided by a pedagogy of kindness. Khan and Armstrong (2019) write about the value of creating academic environments of "loving-kindness" when teaching and encourage educators to embrace being kind as a teaching strategy instead of methods that produce student anxiety. The authors support educator-student relationships based on respect, active listening, and empathy to help reinforce and encourage learning (Khan \& Armstrong, 2019).

Correspondingly, Denial (2019) abandoned her initial approach to teaching, where she thought of students as antagonists and was wary of unethical academic behaviour. After taking several workshops on the use of kindness as a teaching strategy, Denial (2019) now supposes that students are honest and have integrity in their academic work and that they can participate in the teaching and learning process with useful input towards the curriculum.

As well, a case study of two cohorts of university students (and their reflections on academic life) by Groves et al. (2015) concluded that the most significant factor positively impacting student engagement, involvement in academics, and learner success was the educator-student relationship. Further, the students' observations on teacher-student relationships indicated that though they appreciated instructors who were proficient, organized, and animated in the classroom, of more importance and value were those teachers who were welcoming, accessible, and who had a sincere interest in the students' personal and academic lives (Groves et al., 2015).

Loreman (2011) affirms that kindness, as an element of pedagogy, is accepted in the literature as being focal to good teaching and learning and that empathy is "a tool for understanding diversity in areas such as disability, culture, and religion" (p. 16). Thomas (2019), influenced by the works of Catherine Denial and Nel Noddings on the pedagogy of kindness and care, was stirred to reevaluate his teaching strategies. Reflecting on teacher-student and university-student relationships, Thomas (2019) became aware of the reality that these relationships are unequal in power and therefore break "the principle of reciprocity whereby both sides acknowledge and respect the goodwill and endeavours of the other" (para. 11). Thomas (2019) contends that learner-educator relationships should be guided by a teaching model based on kindness, compassion, and care to help amend these power differentials. 
In sum, when educators espouse a teaching philosophy based on a pedagogy of kindness, there are potential advantages for students both personally and academically. Moreover, teachers who are kind in their pedagogical practice can benefit because they become more successful educators. Not only do most students appreciate and prefer this teaching philosophy, being kind as a teaching strategy also builds strong educator-student relationships that improve student engagement in learning and thereby improve learner outcomes. These relationships can also help to diminish unequal power distribution in the teacher-learner dyad. A teaching philosophy guided by a pedagogy of kindness validates the worth and value of each human being.

\subsection{Exemplary Educators and a Pedagogy of Kindness}

The second theme related to links between being an exemplary educator and the employ of a pedagogy of kindness emerged from the analysis. Educators who use this approach have certain attributes and tend to use teaching strategies which result in encouraging effects on the learning environment, positive outcomes for students, and increase learner awareness of social issues.

Worldwide, academics and theorists are endeavoring to understand teaching strategies that produce effective and superior education. Successful and quality teaching approaches are those that concentrate on students and on their learning (Hativa et al., 2001). Henard and Roseveare (2012) note that educators working in higher education institutions are striving to enhance the learning environment for students with the goal of improving student satisfaction and thereby improving student outcomes. Henard and Roseveare (2012) write, "the ultimate goal of quality teaching policies is to improve the quality of the learning experiences of students and through this the outcomes of learning" (p. 9).

The Organization for Economic Cooperation and Development (OECD) highlighted student engagement and learner participation as two critical factors contributing to excellence in teaching and learning (Henard \& Roseveare, 2012). The OECD, according to Henard and Roseveare (2012), emphasized the importance of focusing on students and on their positive learning experiences to help guide the assessment of quality in higher education teaching methods. Acknowledging that students can make valuable contributions to the development of exceptional teaching practices, and inviting students to participate in the establishment of these practices, can build strong and trusting educator-student relationships resulting in more effective teaching approaches (Henard \& Roseveare, 2012). Trust and respect between educators and students impact student outcomes in a productive way (Hativa et al., 2001; Serbati et al., 2020).

The construction of trusting relationships between instructors and learners also has the benefit of fostering caring learning environments where students feel confident in expressing themselves and in sharing their ideas with classmates (Magnet et al., 2014). Feeling comfortable and part of a community, having the freedom to voice opinions, and listening to the divergent thoughts of others, can cultivate intellectual curiosity and help change prejudicial attitudes and promote social justice (Breuing, 2011; Magnet et al., 2014).

A teaching philosophy guided by a pedagogy of kindness has a positive impact on learners. At the University of Toronto, the academic staff made great efforts to connect with students during the COVID-19 pandemic and to create environments of care and kindness through ZOOM classes, videos, and virtual tours to give learners a positive social experience (Vendeville, 2020). Exemplary educators using care, compassion, and empathy as teaching strategies can engage students fully, motivate them, support them, and foster deep educator-student relationships to help promote an enriched learning environment (Hativa et al., 2001).

Serbati et al. (2020) agree, stating that the literature has consistently revealed that exemplary educators are not only organized, animated, and able to communicate with clarity, but they are also empathetic and identify with students. Exceptional teachers have an excellent knowledge of class material, and they present information with enthusiasm to capture students' interest by using innovative techniques during their lessons (i.e., visual aids, creative instructional strategies, and humor), but just as importantly, outstanding educators try to form student-teacher connections based on mutual trust and respect (Hativa et al., 2001; Serbati et al., 2020). These relationships are foundational in stimulating students' engagement, facilitating students' learning, and creating rich and satisfying learning environments that lead to positive learner outcomes and teaching success (Hativa et al., 2001; Serbati et al., 2020). 
As well, exemplary educators are never complacent about their practice. Outstanding teachers are continually evaluating and reevaluating their work and teaching strategies to continue to grow and thrive in an ever-changing academic world (Serbati et al., 2020). Changes such as increased use of technology in education, online learning, internationalization of higher education, and competition among universities around the world make it imperative that educators adapt and continue to provide the highest quality teaching possible (Henard \& Roseveare, 2012). In this sense, educators must continue to use reflection and self-evaluation in their practice, continue to learn new instructional strategies, and be open to feedback from students on the value and effectiveness of their teaching methods (Hativa et al., 2001; Henard \& Roseveare, 2012; Serbati et al., 2020).

It is evident from the literature that exemplary educators using a teaching philosophy based on a pedagogy of kindness that includes empathy and compassion can better adjust to the new developments in higher education. Further, outstanding instructors adopting this teaching philosophy are capable of understanding and identifying with the diversity of students and their individual needs, which can positively impact learner outcomes. Also, inspiring educationalists who use this pedagogical model encourage the expression of different life viewpoints. These exchanges of thoughts promote discussion on issues concerning social justice.

\subsection{Implications for Practice}

While reviewing the literature additional questions came to light. How can we help support exceptional educators to adopt a pedagogy of kindness to advance teaching excellence in our higher education institutions? Further, can a pedagogical model help sustain high-quality teaching?

As Canadians, we have the honour to be ranked first in the percentage of the population who have college or university degrees (in comparison to other OECD countries) (Statistics Canada, 2017). In 2016, 54\% of Canadians (aged 24 to 64) had college or university diplomas as compared to a $37.7 \%$ average in other OECD countries (Statistics Canada, 2017). Contact North (2015), in The future of higher education: A Canadian view, write that though there are a great many positive changes to higher education in Canada (such as access to and success in higher education learning), other changes are not as encouraging. Though the authors comment that some educational institutions are thriving, they note that others are failing, and globally Canada is falling behind in competitive programs and student recruitment (Contact North, 2015). While Canadians have a well-educated population, do we have the most effective educators and the highest levels of student success?

In looking at new developments in the Canadian higher education system, which are also evident around the world, we can see trends that need to be understood so that we can develop and maintain high caliber teaching and learning in our institutions. Internationalization is crucial to the success of our academic institutions. International students can help sustain colleges and universities with revenue, but administrators must ensure staff can meet the needs of (and understand the diversity of) this population (Contact North, 2015). Increasingly instructors are challenged to provide education that is adapted and individualized to students from a wide variety of nationalities. International students will have more influence regarding which teaching strategies are used and on what curricula focus (Contact North, 2015; Henard \& Roseveare, 2012; Serbati et al., 2020).

New technologies and online learning have changed the methods of information and knowledge delivery and improved access to post-secondary learning. These technologies will continue to grow and develop in the coming years (Contact North, 2015). Universities must be ready to incorporate technological teaching and learning methods into their curricula, and educators must be willing and prepared to use technology to be globally competitive (Contact North, 2015; Henard \& Roseveare, 2012). Universities, academic directors, and policymakers must also make continuing education programs (related to topics like technological advances and innovative and effective teaching philosophies) readily accessible to educators so that quality teaching and learning is maintained (Henard \& Roseveare, 2012). As this literature review revealed, a teaching philosophy based on kindness that features teachers who are empathetic and understanding can help support students from diverse backgrounds and can provide a richer learning experience and a more caring and empowering educational environment for all learners. As well, exemplary educators using a kindness focused model can incorporate innovative teaching methods and thus adapt readily to the specific needs of international students and to technological advances in today's academic setting. 


\section{Discussion and Conclusion}

When exploring kindness as an approach to pedagogy in higher education in this literature review several factors became evident. First, the literature reveals that there is a positive and beneficial effect on the learning environment and the outcomes for learners when educators adopt a teaching philosophy based on a pedagogy of kindness (Hativa et al., 2001; Serbati et al., 2020). A teaching model founded on kindness (that includes care and compassion) promotes student engagement, increases learner motivation, and improves learner outcomes. Being kind as a pedagogical strategy is also the foundation for caring student-teacher relationships that provide students with a sense of worth and value as human beings (Clegg \& Rowland, 2010; Groves et al., 2015; Hativa et al., 2001; Serbati et al., 2020; Thomas, 2019). Trusting and mutually respectful relationships between learners and educators also foster caring learning environments that allow students freedom of expression and encourage them to listen to and understand the thoughts, ideas, and experiences of others (Breuing, 2011; Giroux; 1997; Magnet et al., 2014).

Second, the literature demonstrates that there are strong links between being an exemplary educator and adopting a teaching philosophy that uses kindness, empathy, and care in its pedagogy. Outstanding instructors are experts in their subject matter and communicate knowledge with clarity, but they also identify and empathize with students and therefore can better understand and meet the individual and diverse needs of learners (Denial, 2019; Khan \& Armstrong, 2019; Loreman, 2011; Serbati et al., 2020). Inspirational teachers who are kind in their practice are responsible for cultivating a sense of community and kinship among classmates (Clegg \& Rowland, 2010; hooks, 2003; Magnet et al., 2014). The feeling of unity among students, and the sharing of their life experiences enables learners to identify with others and broadens their awareness of social inequities (Breuing, 2011; Clegg \& Rowland, 2010; Giroux; 1997; hooks, 2003; Magnet et al., 2014).

Finally, the literature indicates that there are many new developments and challenges in higher learning for educators, educational administrators, and policymakers. Technological advancements in teaching methods, online and distance education, and the increasing diversity and internationalization of the student population are challenges that are already present and will only grow in the future (Contact North, 2015; Henard \& Roseveare, 2012). To prepare for these ongoing changes, academic administrators must develop strong quality teaching policies that support educators in increasing their knowledge of educational material, new technologies, and teaching strategies that can best support student learning and achievement of learning outcomes (Henard \& Roseveare, 2012; Serbati et al., 2020). Maintaining teaching excellence and providing students with the best chance for academic success (in Canada and globally) should be a universal goal. We must value and support exemplary educators and provide them with all the necessary tools so that they can continue to deliver outstanding teaching (Contact North, 2015; Henard \& Roseveare, 2012). Encouraging a pedagogy of kindness may be one step in giving educators the tools they and students need to succeed.

Acknowledgements. This project was funded by a SSHRC Insight grant.

\section{References}

1. Breuing, M. (2011). Problematizing critical pedagogy. International Journal of Critical Pedagogy, 3(3), 1-23. https://www.marybreunig.com/assets/files/Problematizing\%20Critical\%20Pedagogy.pdf

2. Cambridge University Press. (n.d.). Kindness. In Cambridge Dictionary. Cambridge University Press. https://dictionary.cambridge.org/dictionary/english/kindness

3. Clegg, S., \& Rowland, S. (2010). Kindness in pedagogical practice and academic life. British Journal of Sociology of Education, 31(6), 719-735. http://www.jstor.org/stable/25758494

4. Critical Appraisal Skills Programme (2018). CASP (Qualitative) Checklist. [online] Retrieved October 28, 2020 from https://casp-uk.net/wp-content/uploads/2018/03/CASP-Qualitative-Checklist-2018_fillable_form.pdf.

5. Contact North. (2015). The future of higher education: A Canadian view. https://teachonline.ca/sites/default/ files/pdfs/perspective_on_the_future_of_higher_education.pdf

6. Denial, C. (2019, August 15). A pedagogy of kindness. https://hybridpedagogy.org/pedagogy-of-kindness/ 
7. Edberg, H. (2020). 80 inspirational education quotes for students and teachers. The Positivityblog. https://www.positivityblog.com/quotes-on-education/

8. Giroux, H. (1997). Pedagogy and the Politics of Hope. CA, USA: Westview Press.

9. Groves, M., Sellars, C., Smith, J., \& Barber, A. (2015). Factors affecting student engagement: A case study examining two cohorts of students attending a post-1992 University in the United Kingdom. International Journal of Higher Education. 4(2). http://dx.doi.org/10.5430/ijhe.v4n2p27

10. Hativa, N., Barak, R., \& Simhi, E. (2001). Exemplary university teachers: Knowledge and beliefs regarding effective teaching dimensions and strategies. The Journal of Higher Education, 72(6), 699-729. http://www.jstor.org/stable/2672900

11. Henard, F., \& Roseveare, D. (2012). Fostering quality teaching in higher education: Policies and practices. Paris: OECD. https://www.oecd.org/education/imhe/QT\%20policies\%20and\%20practices.pdf

12. hooks, b. (2003). Teaching Community: A Pedagogy of Hope. New York: Routledge

13. Khan, S., \& Armstrong, A. (2019). Math-a-polka: Mathematics as a place of loving kindness. Journal of the Canadian Association for Curriculum Studies, 17(1), 1-12. https://jcacs.journals.yorku.ca/index.php/jcacs/ article/viewFile/40441/36419

14. Loreman, T. (2011) Kindness and Empathy in Pedagogy. In: Love as Pedagogy. SensePublishers. https://doi.org/10.1007/978-94-6091-484-3_2

15. Magnet, S., Mason, C., \& Trevenen, K. (2014). Feminism, pedagogy, and the politics of kindness. Feminist Teacher, 25(1), 1-22. http://www.jstor.org/stable/10.5406/femteacher.25.1.0001

16. Serbati, A., Aquario, D., Da Re, L., Paccagnella, O., \& Felisatti, E. (2020). Exploring good teaching practices and needs for improvement: Implications for staff development. Journal of Educational, Cultural and Psychological Studies (ECPS Journal), O(21), 43-64. https://doi.org/10.7358/ecps-2020-021-serb

17. Statistics Canada. (2017, November 29). Education in Canada: Key results from the 2016 census. https://www150.statcan.gc.ca/n1/daily-quotidien/171129/dq171129a-eng.htm

18. Thomas, W. (2019, August 23). Pedagogy of care. https://willt486.github.io/teaching/2019/08/23/pedagogy-ofcare/

19. Tyndall, J. (2010, November). AACODS checklist. Flinders University. https://dspace.flinders.edu.au/xmlui/ bitstream/handle/2328/3326/AACODS_Checklist.pdf;jsessionid=0DDDBDF24E5499EDF01FD42AD11513D5?s equence $=4$

20. Vendeville, G. (2020). A pedagogy of kindness: U of T faculty find creative ways to support students, learning during COVID-19. University of Toronto. https://www.utoronto.ca/news/pedagogy-kindness-u-t-faculty-findcreative-ways-support-students-learning-during-covid-19

21. Weiler, K. (Ed.). (2001). Feminist Engagements: Reading, Resisting, and Revisioning Male Theorists in Education and Cultural Studies. New York: Routledge 